\title{
The Study of Automatic Water-saving Device Resettable
}

\author{
Wenbo Bao ${ }^{1, ~ a ~}$, Bo Tang, b, Mengyu Cui ${ }^{1, c}$, Yuxin Zhang, d, and Luan Xu${ }^{3, e}$ \\ ${ }^{1}$ Material science and Engineering, Shenyang Aerospace University, Shenyang 110136, China; \\ ${ }^{2}$ Engineering Training Center, Shenyang Aerospace University, Shenyang 110136, China; \\ ${ }^{3}$ School of Automation, Shenyang Aerospace University, Shenyang 110136, China. \\ a970911006@qq.com,*CorrespondingauthorEmail:b1092786432@qq.com, \\ c782212110@qq.com, ${ }^{d}$ 2543625502@qq.com, ${ }^{e} 1963119056 @ q q . c o m$
}

Keywords: Gas water heater; fully automatic; water-saving; resettable

Abstract: The study of domestic gas water heaters with automatic resettable water saving devices is a national policy call in response to the construction of a resource-saving society, as well as being able to grasp the industry's leading level of technological development and leading the development trend of the industry. At present, large quantities of manufacturers in China have begun the development of zero-water series gas water heaters, and this type of water heater as a representative of research and development strength, after the market went well. However, it is limited by the high price of zero-cooled water-saving household water heaters, and the product specification and models are few. This series of water heaters has not yet achieved the goal of mass production and sales. The paper responded to the national call for energy-saving and water-saving and researched and provided a zero-cooled household gas automatic water-saving device, which effectively solved the problem of wasting water resources, and significantly improved the comfort of water heaters, worthy of further marketing.

\section{Introduction}

Gas water heaters use gas as the main energy source, generate high-temperature heat through combustion of the gas, pass to the cold water flowing through the heat exchanger, and heat the cold water to prepare a hot water heater. With the development of science and technology, the applicability of the gas water heater itself is getting better and better, making the gas water heater into millions of households and becoming a necessity for home life. In the actual use of an ordinary domestic gas water heater, each time a certain amount of cold water needs to be discharged, the hot water can reach the preset temperature, which not only results in the waste of water resources, but also must wait for a certain period of time. Especially when taking a bath, "cold and hot, waiting for hot water for too long" creates a very bad user experience for consumers. "Immediately open and hot" is the trend of product development centered on the consumer and is also one of the hot technologies in the current gas water heater industry. Nowadays, major gas water heater manufacturers have launched or will launch zero-water-type gas water heaters to achieve "i.e., heat," and to solve the two major pain points of "waiting for hot water for too long" and "water temperature in the bath”, China's gas water heater industry will soon enter the "zero cold water" era. My company has recently developed a water heater that can overcome consumer pain points: zero-cooled intelligent constant temperature gas water 
heater. The water heater is optimized on the basis of ordinary gas water heaters, adding circulating pumps and constant temperature water tanks. It is characterized by the fact that not only the instant heat, but also the constant temperature hot water can be quickly spread throughout the house. The dissertation analyzes the design principle of the zero-cold water of the water heater and provides test plans for reference only.

\section{Overall Plan Design and Working Principle of Cold Water-saving Device}

\subsection{Overall scheme of Cold water saving device}

The structure is shown in Figure 1. The function of each section is as follows. Water heaters: Instant water heaters for household use. Temperature detection device: It is composed of a single-chip microcomputer and its auxiliary electronic circuit. According to the received temperature signal, the microcontroller will issue instructions to control whether the two-position three-way solenoid valves are energized or de-energized through the auxiliary electronic circuit. Two-position three-way solenoid valve: equivalent to the role of a switch, when the solenoid valve is de-energized, the left position is connected, when the electromagnet is energized, the right position is connected, thereby controlling the flow of water into different pipelines. One-way valve: Only allow the water that has not reached the temperature to return to the water heater and prohibit the return of cold water. Cold water into the water pipeline: direct access to tap water to provide water. Cold water return pipe: Water that has not reached the temperature returns to the water heater through the pipe to continue heating. Hot water outlet pipe: After the water heater is heated according to the set temperature, the pipe of the water temperature to be detected.

\subsection{Working principle}

The general home water heater working system and principle is shown in Figure 1. When the shower valve is opened, water enters the water heater from the cold-water inlet and passes through the water-gas linkage device. Under the action of the pressure difference of the flowing water, the valve of the water-gas linkage device is opened, the gas solenoid valve is opened, the gas enters, and at the same time the pulse igniter starts ignition. After entering the normal working state, the high-temperature flue gas generated by combustion of the gas heats the heat exchanger. After the cold-water flows through the heat exchanger, the water temperature gradually rises to a preset temperature and is discharged by the shower head for use by people.

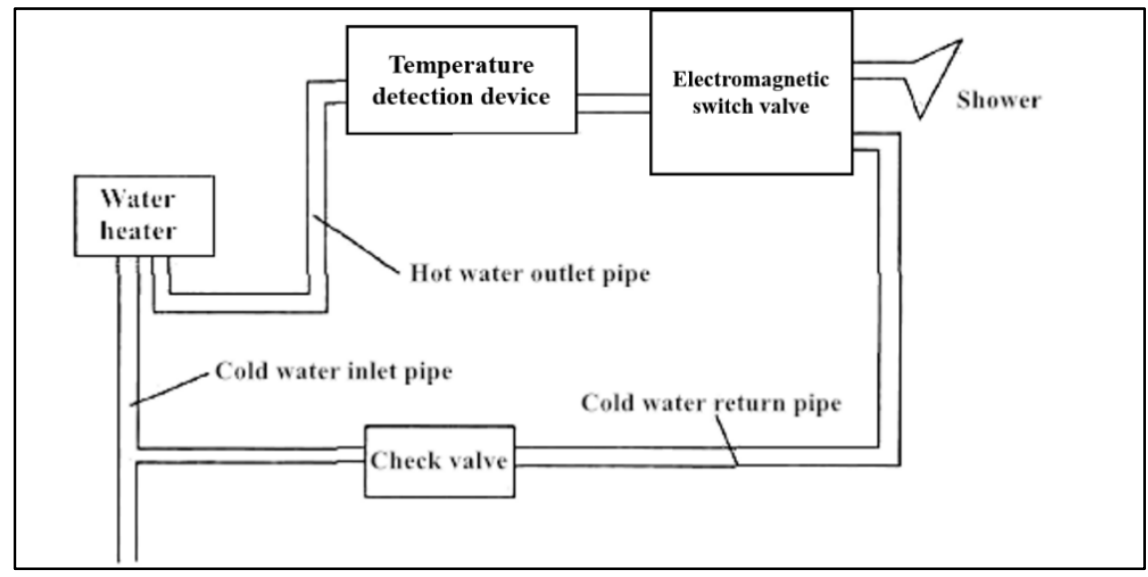

Fig. 1 Water heater cold water recycling device composition 


\section{The Principle and Realization of Intelligent Water-saving Device}

\subsection{Hardware Design Principle of Intelligent Water-saving Device}

The basic principle of the intelligent water-saving device is as follows: when the user opens the water inlet and the gas-fired water heater is running, the temperature sensor detects the water temperature, and the temperature is used as the input signal of the monolithic L. The single-chip microcomputer issues an instruction to control the electromagnetic of the electromagnetic reversing valve. Iron or power loss, so that the valve to open the same valve. If the water does not reach the set temperature, that is, "cold water", the MCU sends an instruction to make the solenoid valve switch to the right position of the valve and the water flows back to the inlet and the heater reheats. If the water reaches the set temperature, that is, "hot water", the MCU sends an instruction to make the solenoid valve close to the left position of the valve and the water flows directly to the spray head for use by the user.

\subsection{Pipeline Connection System of Zero Chiller}

Zero-water-type gas water heater in the design of the body to increase the factory back to the water pipeline interface, whether it is new home decoration or old room dress, can be used. The external pipeline connection scheme is mainly divided into two types: one is to set a one-way pipeline in parallel with the water mixing valve of the water point between the outlet pipe and the cold-water pipe for supplying the cold water, so that the water heater and the outlet pipe Parallel piping and cold-water pipes form a circulation pipeline. The design principle of the piping system is shown in Figure 2. This scheme makes full use of the original cold-water piping in the plant user's home, and the user does not need to reconstruct the existing piping design. Zero-cold water circulation is realized and the construction is relatively simple.

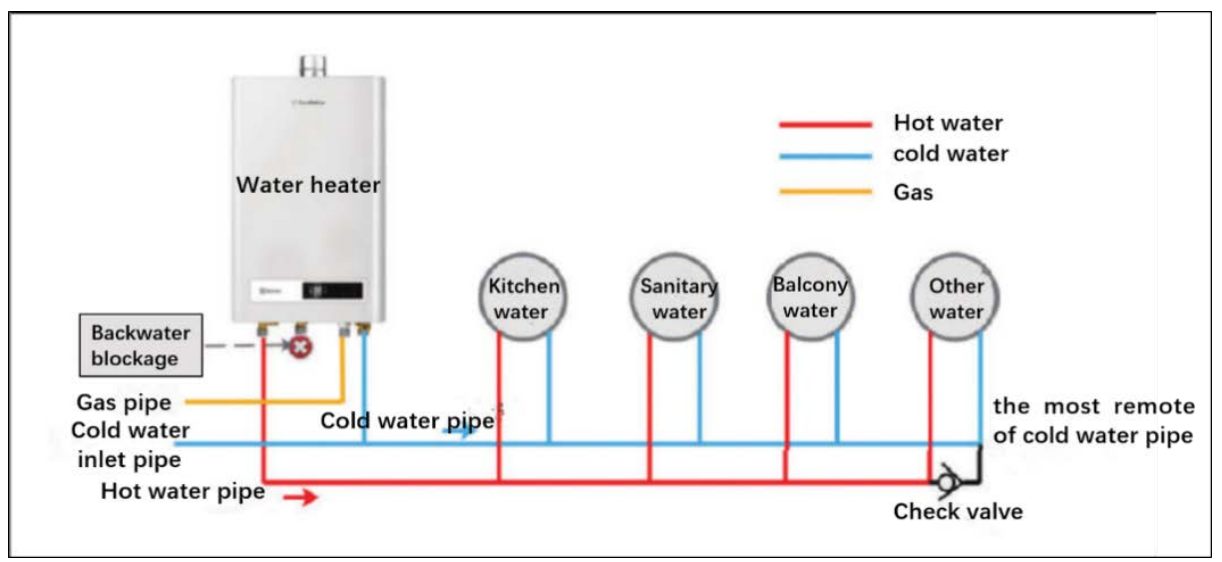

Fig. 2 No water return pipeline zero cold water heater pipe connection system diagram

\subsection{Hardware Implementation Circuit of Intelligent Water-saving Device}

Temperature detection device design circuit shown in Figure 3, the temperature detection device circuit selected 89C51 series microcontroller as the core component, because 89C51 contains $4 \mathrm{~KB}$ of EEPROM in the chip, and then need a separate external expansion memory, can simplify the overall structure of the system. Using the 89C51 serial port output, also simplifies the external circuit, the serial output data, the frequency up to $1 \mathrm{MHz}$, to meet the system's measurement and control requirements.

The temperature measurement selects the integrated temperature sensor AD590. The sensor has 
high accuracy. In addition, the auxiliary power supply is small. The circuit structure is simple and easy to implement, and the linearity of the acquisition result is good.

Daily life, gas water heater temperature change range will be too small, the minimum temperature resolution is $10 \mathrm{C}$, water temperature range of $0-1000 \mathrm{C}$, so the entire intelligent temperature control system temperature acquisition point should be 200, 8-bit AD conversion the resolution of the device is $1 / 256$, which satisfies the requirement of gas water heater temperature conversion accuracy. Successive approximation A/DC has high conversion speed, fixed conversion program and high precision, so this system selects 8-bit successive approximation A/D converter ADC0809.

When the pin P3.1 of the single-chip microcomputer 89C51 is at a high level, it goes low through the inverting driver 7406 to turn on the light-emitting diode, so that the phototransistor is turned on, the transistor T9031 is operated, the relay coil is energized, and the contacts are closed, $220 \mathrm{~V}$ voltage is connected, that is, the electromagnetic valve reversing valve is energized, and the water flows out of the shower.

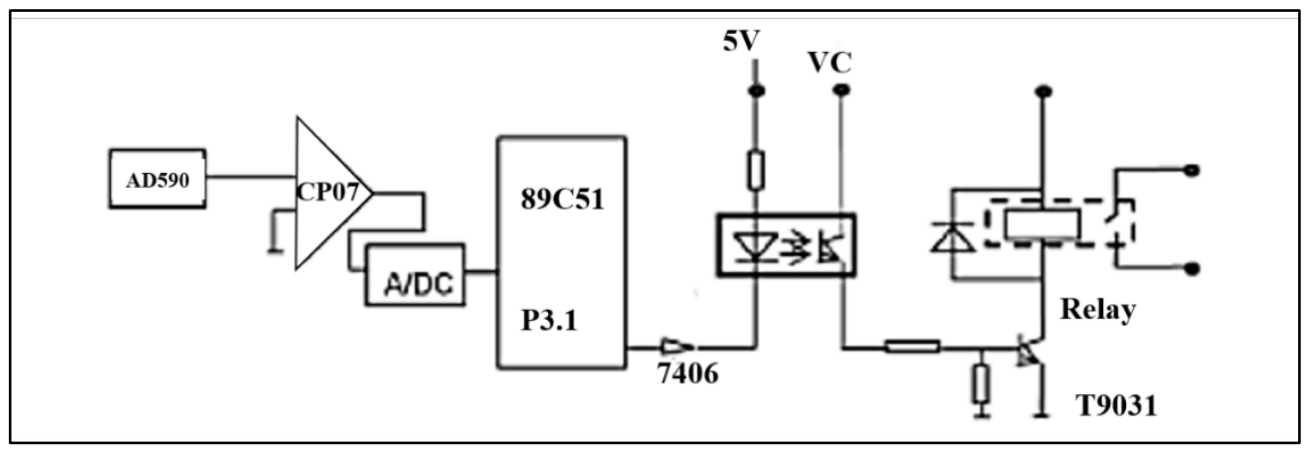

Fig.3 Temperature detection device circuit diagram

Solenoid valves are the basic automation components used to control fluids. They control mechanical motion by controlling the electromagnet current. For the convenience and accuracy of control, the device controls all the solenoid valves through one instruction during design, which reduces the complexity and failure rate of the program.

According to the system requirements, first select an electromagnetic reversing valve used in the oil circuit and design a suitable valve in the waterway according to actual requirements. Under normal circumstances, the household water supply pressure is $0.4 \mathrm{MPa}$, after this pressure value can be tap water into the water heater, assuming residents water from the water heater outlet is about $8 \mathrm{~m}$ away, the temperature is about $40{ }^{\circ} \mathrm{C}$, then the inlet pressure is $\mathrm{p}=\rho g \mathrm{v}$. According to the pressure $\mathrm{F}$ of the water, select the appropriate electromagnet and select the GMP permanent magnet under the SCHULTZ brand. The coil can be used in NASS original Germany and can be used directly. The material of the entire valve body is copper. After the armature pulls in, it drives the push rod to move, thereby changing the position of the step and changing the flow of water.

In the process of using the entire system, due to the need to change the flow of water, so that cold water that has not reached the temperature re-introduced into the heating chamber, then the design of the pipeline must take into account whether the problem of whether the water will backflow. A check valve is added at the outlet of the cold-water pipe to ensure that the water can only flow in one direction and not in the other direction. At the same time, the one-way valve should be installed at the lower end of the cold-water inlet during the assembly process to ensure that the cold water does not flow back according to the area. For this one-way valve design, the design of the spring is also particularly important. Taking into account the ease of installation, the use of straight-through check valve, rely on the role of the valve spring to open or close the valve port, then the water pressure must be greater than the spring pressure. 
When the shower valve is opened and the water saving device is automatically turned on, the SCM control system starts to retrieve the signal sent from the temperature sensor. When the temperature does not reach the set temperature, the control system controls the solenoid valve and the cold water flows back; when the temperature reaches the set temperature, the single chip output with the control command, the water heater enters the normal operating state, and the water saving device enters standby.

\section{Experiment Analysis of Zero-water Gas Water Heater}

To simulate the actual use of the zero-cold-water gas water heater, the experimental principle research platform as shown in Figure 6 was designed. The electric water heater was used to simulate the user's return water pipeline, which invalidated the heating system of the electric water heater, allowing only its temperature detection function to display the tank. Water temperature, build an experimental platform, and verify the actual performance of zero-cold water gas water heaters by controlling the ball valve switches at various locations.

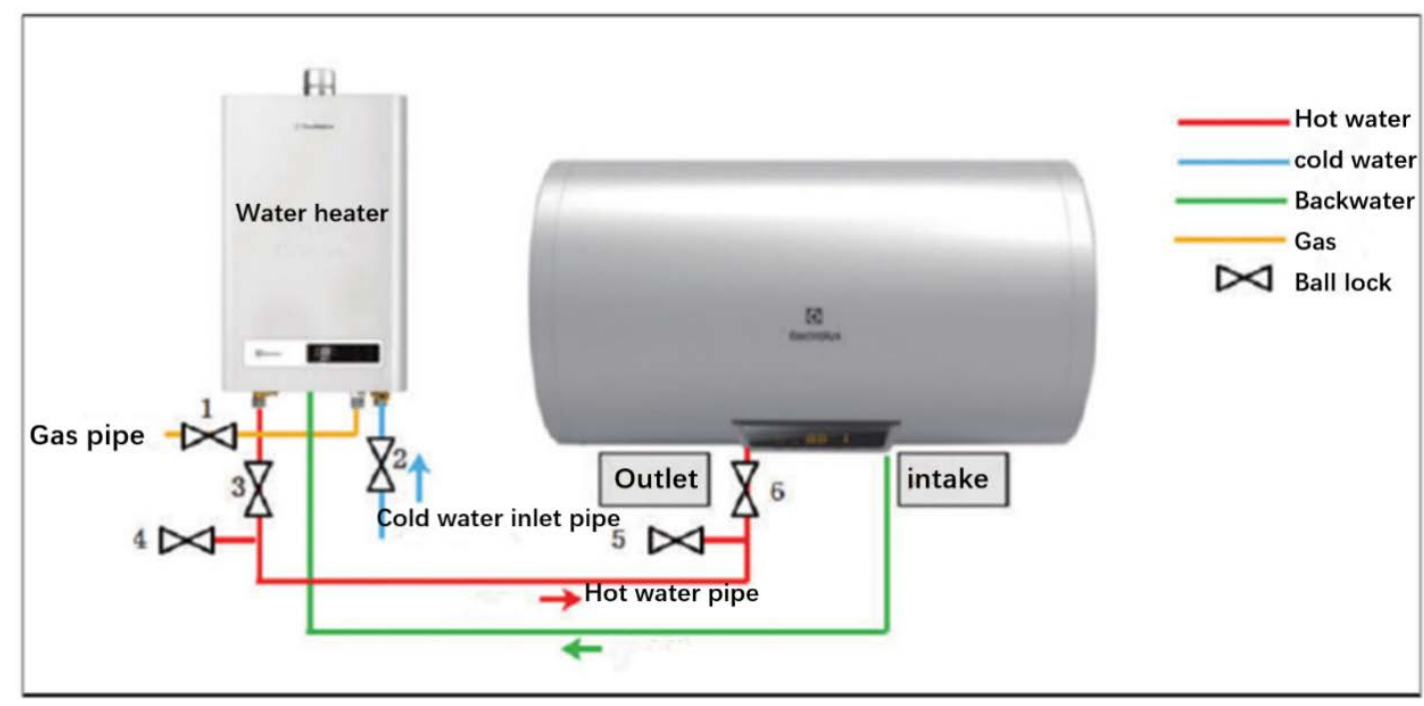

Fig.4 Experimental schematic

The experimental steps are as follows:

(1) Open the 1,2,3,4 ball valve and close the ball valve 5,6 to verify that the water heater is working properly;

(2) Open the 2, 3, 5, 6 ball valve and close the ball valve 1, 4 until the ball valve 5 has water flow out, which means that the water heater tank is filled with water;

(3) Open the 1, 3, 6 ball valve, close the ball valve 2, 4, 5, start the water heater zero cold water circulation heating mode;

(4) Wait until zero cold water preheat mode operation stops, record the water temperature of the electric water heater liner and compare it with the set temperature value. The results are shown in Table 1.

Tab.1 Comparison of experimental simulation data

\begin{tabular}{|c|c|c|}
\hline set temperature $\left({ }^{\circ} \mathrm{C}\right)$ & measure temperature $\left({ }^{\circ} \mathrm{C}\right)$ & Measurement deviation $\left({ }^{\circ} \mathrm{C}\right)$ \\
\hline 35 & 35.7 & 0.7 \\
\hline 38 & 38.4 & 0.4 \\
\hline 40 & 40.4 & 0.4 \\
\hline 42 & 42.8 & 0.8 \\
\hline
\end{tabular}


The experimental results show that the error between the water temperature and the set temperature of the inner water heater of the electric water heater does not exceed $1 \mathrm{~K}$, indicating that the zero-cold water function is operating normally.

\section{Conclusion and Prospects}

This article uses a single-chip microcomputer and a temperature detection device to separate and reach the set temperature water, and automatically recognizes the "cold" and "hot" water flow channels so that the electromagnetic directional valve will not reach the preset temperature water and reach the preset temperature. The water separation makes it possible to recycle the cold water left in the pipes of the water heater and the shower nozzle. This can save water and solve the problem of large amounts of wasted water, realizing the intelligence and automation.

\section{Acknowledgments}

This work is partly supported by College Students Creation and Career Training Project of Shenyang Aerospace University in years of 2018, (No. 110418105) (No. 110418106) and (No. 110418107).

\section{References}

[1] Yang Wenqiang, Liu Shusong. Energy-saving water supply system design of solar water heater based on HT46R23 single-chip microcomputer control. Journal of Anhui Agricultural Sciences, Vol. 6 (2012) NO. 27, p. 3776-3778.

[2] ZHANG Guoyi, LIU Aisao. Water Saving Design and Research of Gas Water Heater. Anhui Architecture, Vol. 3 (2015) NO. 34, p. 180-182.

[3] Ma Zhiyan. Design and research on the design and application of automatic water-saving device for domestic water heater cold water. Machinery and Electronics, Vol. 9(2014) NO. 12, p. 23-25.

[4] Yin Dangui, Wang Qiong Research and Design of Intelligent Water-saving Device for Gas Water Heater Popular Science and Technology, Vol. 2(2016) NO. 18, p. 43-47. 